\title{
Hemodynamic response to prone ventilation in COVID-19 patients assessed with 3D transesophageal echocardiography
}

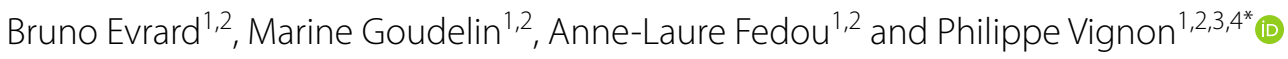

๑ 2020 Springer-Verlag GmbH Germany, part of Springer Nature

Dear Editor,

Prone positioning (PP) is proposed in ventilated patients for acute respiratory distress syndrome (ARDS) due to Corona Virus Disease-19 (COVID-19) [1]. Hemodynamic assessment using transesophageal echocardiography (TEE) is proposed during PP in COVID-19 patients [2]. We sought to assess the hemodynamic response to PP using real-time three-dimensional (RT3D) TEE in patients with moderate-to-severe COVID-19 ARDS.

Ventilated patients with confirmed COVID-19 ARDS underwent a RT3D TEE assessment immediately before, $1 \mathrm{~h}$ after PP, and $16 \mathrm{~h}$ later back to supine position (Supplementary materials). Results are expressed as medians and 25th-75th percentiles.

Nine patients were studied, all being hemodynamically stable without vasopressor support or other organ failure (Supplementary Table 1). Despite mild acute pulmonary hypertension, the right ventricle (RV) was not dilated as reflected by normal indexed end-diastolic volume (RVEDVi). Cardiac index (CI), RV and LV ejection fraction (EF) and strain rate were normal (Supplementary Table 2). All patients responded to $\mathrm{PP}\left[\mathrm{PaO}_{2} /\right.$ $\mathrm{FiO}_{2}: 127$ (94-141) vs. 77 (67-94): $\left.p=0.012\right]$. During PP, RVEDVi and LVEDVi decreased (Fig. 1), while respective EF and strain rate remained stable. Back in supine position, RVEDVi and LVEDVi increased but remained within normal range (Fig. 1), while biventricular EF, CI and strain rate kept steady. LV end-systolic eccentricity index (ESEI) normalized during PP and returned to

\footnotetext{
*Correspondence: philippe.vignon@unilim.fr

${ }^{4}$ Réanimation Polyvalente, CHU Dupuytren, 2 Avenue Martin Luther King, 87042 Limoges, France

Full author information is available at the end of the article
}

baseline values back in supine position (Supplementary Tables 2 and 3).

One patient had moderate acute cor pulmonale (ACP) with preserved LV systolic function at baseline. During PP, RVEDVi decreased and paradoxal septal motion disappeared, as reflected by a normalized LVESEI (Fig. 1). Despite normal mean blood pressure, CI, LVEF and LV strain rate decreased from 5.0 to $3.6 \mathrm{~L} / \mathrm{min} / \mathrm{m}^{2}, 61 \%$ to $35 \%$, and $-20 \%$ to $-14 \%$, respectively, whereas systemic vascular resistances (SVR) remained low (from 950 to $989 \mathrm{mmHg} / \mathrm{L} / \mathrm{min}$ ). The patient developed oliguria. A 1.5L fluid challenge was performed due to preloaddependence (Fig. 1). Back in supine position, hypotension occurred secondary to a drop of CI to $2.25 \mathrm{~L} / \mathrm{min} / \mathrm{m}^{2}$ despite normalized SVR $(1500 \mathrm{mmHg} / \mathrm{L} / \mathrm{min})$. Moderate ACP recurred as reflected by increased RVEDVi and LVESEI, while both LVEF and LV strain rate decreased to $25 \%$ and $-13 \%$, respectively, in the absence of preload dependence (Fig. 1). Kidney function subsequently deteriorated (creatinine: $71 \mu \mathrm{mol} / \mathrm{L}$ to $220 \mu \mathrm{mol} / \mathrm{L}$ ).

During PP, RT3D echocardiography which has been validated against MRI [3], depicted a transient decrease of ventricular volumes which was not tracked by twodimensional imaging (Supplementary Table 4), and a non-significant decrease of LV stroke volume compensated by increased heart rate. The significant yet reversible decrease of RVEDVi and normalization of LVESEI confirm the beneficial effect of PP on afterloaded RV [4]. Despite the transient reversal of a moderate ACP, one of our patients developed severe LV systolic dysfunction with decreased $\mathrm{CI}$ and altered myocardial contractility. This resulted in a worsened low flow state and subsequent acute renal failure. TEE during PP was well-tolerated [5]. Although this observational study is limited by 


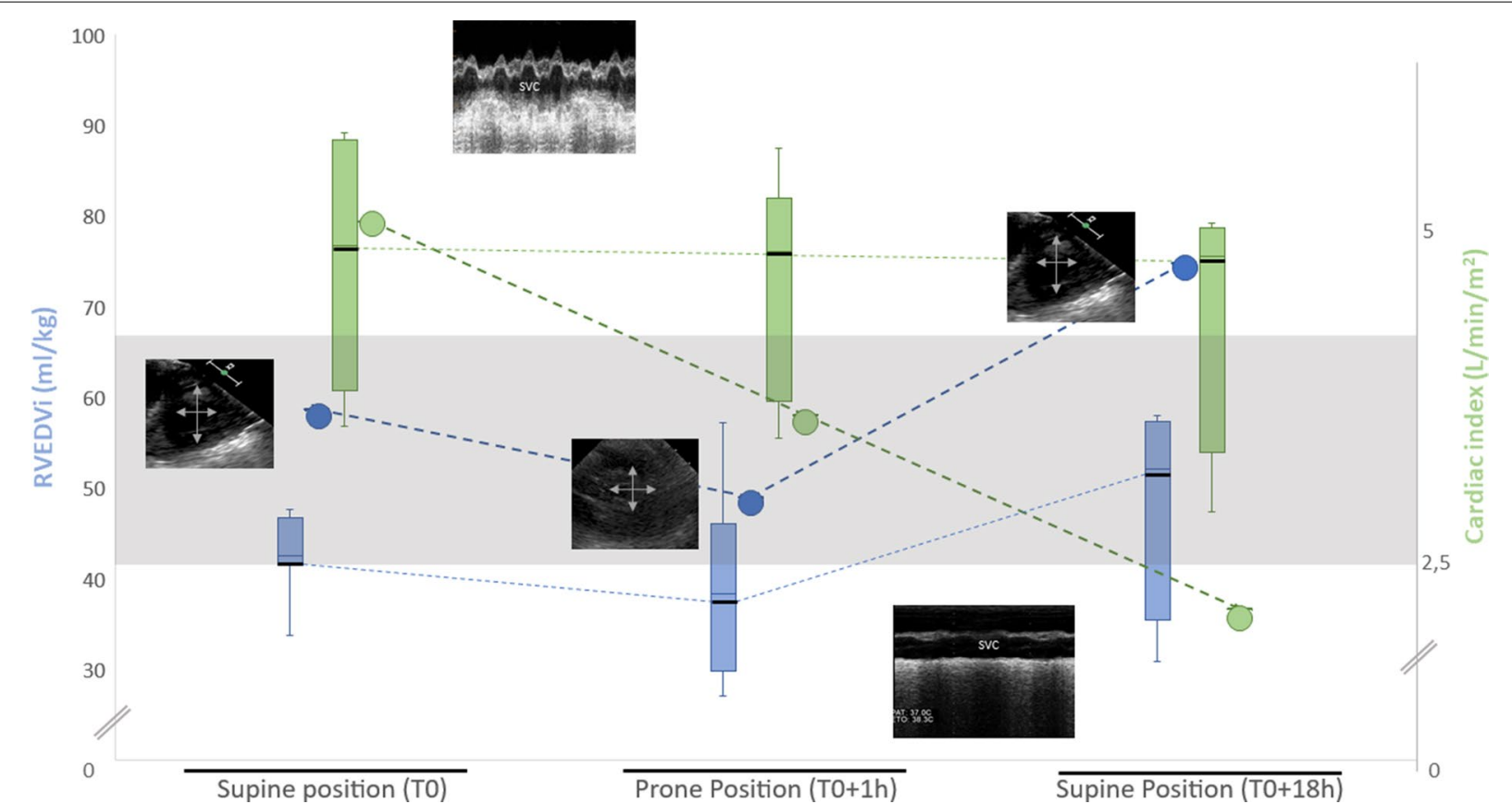

Fig. 1 Variations of indexed right ventricular end-diastolic volume and cardiac index during and after prone positioning in the study group $(n=8)$ with stable hemodynamics and in the single patient who deteriorated his hemodynamic status. Variations of indexed right ventricular end-diastolic volume (blue symbols) during and after prone ventilation are plotted with those of cardiac index (green symbols), when using baseline as reference. Box plots indicate median (thick horizontal bar), 25th and 75th percentiles (bottom/top of the boxes), as well as 5th and 95th percentiles (thin horizontal bars). Closed circles indicate individual values of indexed right ventricular end-diastolic volume and cardiac index in the patient who deteriorated during and after prone positioning. Dotted lines connect median and dashed lines connect individual values. The grey area indicates the normal range of indexed right ventricular end-diastolic volume measured with RT3D TEE. In the single patient who deteriorated, preloaddependence was identified by significant superior vena cava (SVC) collapsibility index at baseline and $1 \mathrm{~h}$ after prone positioning (upper left panel). A 1.5L fluid challenge reduced SVC collapsibility index (lower right panel) but failed to avoid further deterioration of cardiac index. The transgastric short-axis view of the heart depicted a moderate cor pulmonale at baseline, with an end-systolic eccentricity index of 1.5 (lower left panel) which transiently normalized close to unity during prone positioning (lower middle panel). Moderate cor pulmonale resumed after return to supine position with an end-systolic eccentricity index of 1.4 (upper right panel)

its small sample size and warrant confirmation, it suggests that RT3D TEE monitoring is feasible and promises to track individual hemodynamic response to PP which may unpredictably be deleterious.

\section{Electronic supplementary material}

The online version of this article (https://doi.org/10.1007/s00134-020-06217 -w) contains supplementary material, which is available to authorized users.

\section{Author details}

${ }^{1}$ Medical-Surgical Intensive Care Unit, Dupuytren Teaching Hospital, 87000 Limoges, France. ${ }^{2}$ Inserm CIC 1435 and UMR 1092, Dupuytren Teaching Hospital, 87000 Limoges, France. ${ }^{3}$ Faculty of Medicine, University of Limoges, 87000 Limoges, France. ${ }^{4}$ Réanimation Polyvalente, CHU Dupuytren, 2 Avenue Martin Luther King, 87042 Limoges, France.

\section{Author contributions}

$\mathrm{BE}$ and PV designed the study. BE, MG, ALF included the patients and performed the echocardiography. BE and MG reviewed off-line all echocardiography studies. BE and PV drafted the manuscript. MG and ALF critically reviewed the manuscript. All authors read and approved the final manuscript.

\section{Funding}

None.

\section{Compliance with ethical standards}

\section{Conflicts of interest}

The authors declared that they have no conflict of interest.

\section{Ethical approval}

Ethical Committee accepted this observational study and waived the need for informed consent

\section{Publisher's Note}

Springer Nature remains neutral with regard to jurisdictional claims in published maps and institutional affiliations.

Accepted: 13 August 2020

Published online: 26 August 2020

\section{References}

1. Gattinoni L, Chiumello D, Caironi P, Busana M, Romitti F, Brazzi L, Camporota L (2020) COVID-19 pneumonia: different respiratory treatments for different phenotypes? Intensive Care Med 46:1099-1102

2. Teran F, Burns KM, Narasimhan M, Goffi A, Mohabir P, Horowitz JM, Yuriditsky E, Nagdev A, Panebianco N, Chin EJ, Gottlieb M, Koenig S, Arntfield $R$ (2020) Critical care transesophageal echocardiography in patients 
during the COVID-19 pandemic. J Am Soc Echocardiogr. https://doi. org/10.1016/j.echo.2020.05.022

3. Shimada YJ, Shiota M, Siegel RJ, Shiota T (2010) Accuracy of right ventricular volumes and function determined by three-dimensional echocardiography in comparison with magnetic resonance imaging: a meta-analysis study. J Am Soc Echocardiogr 23:943-953

4. Vieillard-Baron A, Charron C, Caille V, Belliard G, Page B, Jardin F (2007) Prone positioning unloads the right ventricle in severe ARDS. Chest 132:1440-1446
5. Mekontso Dessap A, Boissier F, Charron C, Bégot E, Repessé X, Legras A, Brun-Buisson C, Vignon P, Vieillard-Baron A (2016) Acute cor pulmonale during protective ventilation for acute respiratory distress syndrome: prevalence, predictors, and clinical impact. Intensive Care Med 42:862-870 